\title{
La destrucción de los mitos nacionales en Arturo Cancela
}

\author{
Destruction of National Myths in Arturo Cancela \\ A destruição dos mitos nacionais em Arturo Cancela
}

\section{Adriana Rodríguez Pérsico}

\section{UNIVERSIDAD DE BUENOS AIRES / CONICET, ARGENTINA}

Profesora Asociada de la Facultad de Filosofía y Letras de la Universidad de Buenos Aires, Argentina. Investigadora de CONICET. Doctora en Letras, Universidad de Buenos Aires. Co-autora, con Jorge Fornet, de Ricardo Piglia: una poética sin límites (Pittsburgh: University of Pittsburgh, 2004), y autora de Un huracán llamado progreso: utopía y autobiografía en Sarmiento y Alberdi (Washington: Organización de los Estados Americanos/INTERAMER, 1992; 2a . ed. 1993), Relatos de época: una cartografía de América Latina (1880-1920) (Rosario: Beatriz Viterbo Editora, 2008) y Brindis por un ocaso: de los escritores nacionales a los humoristas porteños (Buenos Aires: Santiago Arcos, 2010). Ha publicado artículos en diversas revistas especializadas de Estados Unidos, América Latina y Europa. Correo electrónico: apersico@conicet.gov.ar

\footnotetext{
Artículo de reflexión

Documento accesible en línea desde la siguiente dirección: http://revistas.javeriana.edu.co doi: 10.11144/Javeriana.cl20-39.dmna
} 


\section{Resumen}

Durante las décadas de 1920 y 1930, en Argentina, una serie de escritores y periodistas -Arturo Cancela, entre ellos- ejercitan en medios de gran tirada la crítica política que apunta al gobierno radical llegado al poder en 1916. Mezclando costumbrismo y humor y usando formas breves o fragmentarias, muestran un país entre la ruina de las instituciones. $\mathrm{Al}$ mismo tiempo, realizan una operación de desmitificación de los grandes relatos nacionales de comienzos de siglo XX, momento de celebración del Centenario de la Revolución de Mayo.

Palabras clave: mitos; identidad nacional; literatura argentina

\section{Abstract}

In Argentina, during the 1920s

and the 1930s, a group of writers and journalists -Arturo Cancela among them- exercise in broadsheets political critic aimed at the radical government that took over power in 1916. Using a blend of costumbrismo and humor, and using short or fragmented forms, they show a country lying in the ruins of the institutions. At the same time, they carry out a demythification operation of great national narratives of the early 20 th century, the moment of the Hundredth Anniversary Celebration of the May

Revolution.

Keywords: myths; national identity; Argentinian literature

\section{Resumo}

Durante as décadas de 1920 e 1930, na Argentina, uma série de escritores e jornalistas -Arturo Cancela, entre elesexercitam na grande mídia a crítica política que aponta para o governo radical chegado ao poder em 1916. Misturando costumbrismo e humor e usando formas curtas ou fragmentárias, mostram um país entre a ruina das instituições. Ao mesmo tempo, fazem operação de desmitificação dos grandes relatos nacionais de começo de século XX, momento de comemoração do Centenário da Revolução de Maio.

Palavras-chave: mitos; identidade nacional; literatura argentina

RECIBIDO: 12 DE MARZO DE 2015. ACEPTADO: 20 DE ABRIL DE 2015. DISPONIBLE EN LÍNEA: 01 DE ENERO DE 2016

Cómo citar este artículo:

Rodríguez Pérsico, Adriana. "La destrucción de los mitos nacionales

en Arturo Cancela". Cuadernos de Literatura 20.39 (2016): 191-

200. http://dx.doi.org/10.11144/Javeriana.cl20-39.dmna 
DURANTE LAS DÉCADAS de 1920 y 1930, en Argentina, una serie de escritores y periodistas - Arturo Cancela, entre ellos- ejercitan, en medios de gran tirada como La Nación, El Hogar y Caras y Caretas, la crítica política que apunta al gobierno radical llegado al poder en 1916 en elecciones, por primera vez, no fraudulentas. Con dos presidencias de Hipólito Yrigoyen, la segunda interrumpida, y una de Marcelo T. de Alvear, el período radical se extiende hasta 1930, año en el que un golpe militar encabezado por el General Uriburu quiebra el orden democrático, dando lugar a lo que se llamó La década infame.

Mezclando costumbrismo y humor, estos textos escritos en formas breves o fragmentarias muestran un país entre la ruina de las instituciones. Al mismo tiempo, realizan una operación de desmitificación de los grandes relatos nacionales de comienzos de siglo Xx, momento de celebración del Centenario de la Revolución de Mayo cuando escritores como Rojas, Lugones o Gálvez se dan a la tarea de crear un pasado para sembrar con memorias lo que veían como un desierto cultural e histórico en ensayos monumentales y totalizadores. Los relatos nacionales construyen la memoria colectiva y, en consecuencia, funcionan como archivos que guardan las tradiciones y arman genealogías dando testimonio de un pasado primigenio concebido como un tesoro a preservar.

Arturo Cancela rastrea los mitos constructores de una tradición para demolerlos mediante una poética antimimética y antirrealista. Sus personajes carecen de densidad y la geografía y los paisajes parecen de cartón ${ }^{1}$. En 1930, escribe:

Por desgracia yo no creo en los mitos; y digo por desgracia porque mi incredulidad en ellos me impide escribir libros de aliento. La fe en los mitos literarios, históricos y sociológicos es, por cierto, el mayor aliciente de la producción artística. El mito del gaucho ha dado origen a Don Segundo Sombra; el del indianismo a casi toda la obra de Rojas; el del helenismo al Payador, a las Industrias de Atenas y a las traducciones homéricas de Leopoldo Lugones; el del hispanismo al Solar de la raza de Manuel Gálvez, a Las bodas de Don Fuan de Carlos Noel y a otras equivalentes. (Cancela, "Helenismo en la pampa" 12) ${ }^{2}$

1 Dice Bernini: "La oralidad formará parte inescindible de sus textos mediante un amplio cuerpo de registros yuxtapuestos: el voseo, las lenguas extranjeras, las traducciones, cuyos equívocos constituirían otra lengua - si consideramos así las paronimias y las aliteraciones-, las lenguas de las multitudes ('horrísonas', 'llenas de inconveniencias') y las lenguas de la escritura, en particular, la lengua cosificada de los discursos políticos y culturales, blanco de su obstinado ataque" (247).

2 Recordemos que Gálvez escribió una Historia de arrabal y que tanto Larreta, como Rojas o Lugones inventan genealogías prestigiosas y edulcoradas que remontan a nobles antigüedades. 
Contra los mitos literarios del gaucho, el indianismo, el helenismo y el hispanismo, tomados como núcleos de la identidad nacional, Cancela opta por los caminos oblicuos de la parodia, la cita, la ironía, el collage, el dislate, la apelación a literaturas lejanas en tiempo y espacio. Escepticismo y nihilismo se entrelazan para impugnar las esencias de la identidad que encarna el héroe. Si el héroe es fuente de sentido que anuda en sí la totalidad del mundo ficcional, sus textos imaginan puros seres discursivos que son acumulación caótica de retazos oratorios.

Cancela desmitifica figuras que encarnan valores políticos de la nacionalidad, instituciones, saberes consagrados y también lenguajes científicos, políticos, mediáticos mostrando falacias y contradicciones. En cuentos como "El culto de los héroes" - incluido en Tres relatos porteños (1922) - o "Cacambo" (1920) desnuda operaciones de montaje del panteón nacional. En el primero, la vida anodina de un inmigrante adquiere ribetes épicos gracias a las versiones públicas difundidas por la prensa tras la muerte del protagonista. Tres generaciones aprietan la historia del país: el padre - antiguo afilador y dueño de una empresa de transportes - encarna el trabajo esforzado y la recompensa material; la hija, el afán de figurar y el rechazo de una ascendencia plebeya; y el nieto, una vida de holgazanería y parasitismo.

Por su parte, "Cacambo" es un relato sobre la identidad nacional que toma al personaje de Voltaire - tucumano en Candide - como símbolo de la argentinidad. El diálogo se entabla entre el profesor Herrlin que convierte al criado en un filósofo y don José Manuel Inclán Zavaleta, "apasionado cultor de la historia patria". Con perspicacia, Zavaleta le retruca que Cacambo es un sirviente, mientras el sueco insiste en que estar al servicio del espíritu enaltece. A partir de esta conversación, el argentino escribe un ensayo que publica en la revista del Museo Histórico donde coloca al personaje en el panteón de los héroes al lado del sargento Falucho, Lucía Miranda o Martín Fierro ${ }^{3}$.

Pero Cancela no solo se dedica a demoler los pilares de la tradición. Entre los mitos culturales contemporáneos que corroe se encuentran el del especia-

3 Para el tema del nacionalismo, puede verse el ensayo de Raúl Antelo "Cancela: humor, nacionalismo e historia". Refiriéndose a la Segunda parte de Zadig: "Así pues, para articular áreas de problemas, Cancela procede a evitar el realismo: salta el siglo XIX y vuelve a Voltaire" (257). "Si Voltaire critica en Zadig filosofías que más parecen novelas (con lo cual funde géneros y crea el cuento filosófico), Cancela discute sociologías noveladas que toman y retoman (ideologizándolo) el tópico de ser nacional. Lo argentino, para Cancela antes que para Borges, está en la mirada del otro. Ni ciencia ficción, ni filosofía ficción, la Segunda parte de Zadig es algo así como una ficción histórica. No la novela histórica al modo de Larreta. Cancela, como Ménard, con toda naturalidad, elude lo típico. No sin ironía por lo demás, su novela apocalíptica $L a$ mujer de Lot está dedicada, justamente, a Larreta" (257-258). 
lista extranjero, hombre de ciencia, humanista, filósofo o escritor y el orador de principio de siglo, fusión de hombre de letras, político y profeta. En el contexto de un sofocante espíritu nacionalista que hurga en esencias telúricas, lingüísticas, étnicas y culturales, Cancela hace una literatura que se ríe de las ilusiones proféticas de extranjeros o nacionales. En su notable Historia funambulesca del profesor Landormy (1944), el protagonista es un arqueólogo francés que arriba a Buenos Aires para dar una serie de conferencias sobre la antigua cultura cretense. El diseño del personaje cabe en el estereotipo del profesor distraído. Las cosas se derrumban a su alrededor, pero él se entera siempre $a$ posteriori.

A los viajeros ilustres que llegaban por entonces al país se les otorgaba el don y el privilegio de desentrañar la identidad nacional. Los argentinos necesitaban que el extranjero les develara el enigma de la identidad. Con motivo de la celebración del cuarto centenario de la primera fundación de Buenos Aires, en 1936, la municipalidad auspicia un ciclo de disertaciones radiofónicas transmitidas por la difusora del Teatro Colón, a cargo de intelectuales y escritores reconocidos, entre ellos Borges y Cancela que hablan de esta figura del ilustre visitante (Homenaje a Buenos Aires).

En "Buenos Aires a vuelo de pájaro", Cancela esboza tópicos que aparecerán desarrollados en Historia funambulesca. El interrogante dirigido al forastero desencadena la búsqueda de soluciones:

En estos días pasados, como siempre que tenemos visitas de categoría, el buen público porteño ha leído el inevitable reportaje al huésped ilustre. Cualquiera que sea la forma que adopte y por grandes que sean sus desviaciones, es bien sabido que, al principio, en su transcurso o hacia el final, surgirá la pregunta ineludible:

“¿Qué le parece a usted Buenos Aires?”. (Homenaje a Buenos Aires... 535)

Decíamos que la otra figura parodiada es la del orador parlamentario. Muchos han visto en el personaje del doctor Izquierdo de Historia funambulesca la representación del legislador socialista Alfredo Palacios. El famoso orador sintetiza la mezcla vernácula de anacronismo y vacío conceptual. Los discursos parlamentarios son refritos de fragmentos de discursos pronunciados en otras circunstancias, de citas forzadas porque se usan inalterables en los contextos más disímiles, de frases hechas y lugares comunes. El orador es un actor que recita párrafos altisonantes atendiendo no al sentido sino a los efectos de la puesta en escena. Más allá de las referencias al sujeto real, el texto se burla de un tipo de mucho peso hacia finales de siglo XIX y principios del XX. Basta recordar el caso de Lugones, un hablador impenitente que lanzaba su palabra oracular en banquetes, 
ateneos, actos oficiales o académicos y que intentó marcarle rumbos discursivos al mismísimo gobierno de Uriburu.

Cancela pone la mirada en los discursos políticos mucho antes de Historia funambulesca. En Film porteño, publicada en 1933, incluye numerosas cartas. En una de ellas, titulada "Qué es la cultura", con fecha 19 de julio de 1930, el personaje principal, Nasute, describe al "amigo cronista" el desatino y la vacuidad de la incultura parlamentaria exhibida en discursos "sin medida, sin proporciones, escritos en un idioma bárbaro que a ratos se parece al castellano, relumbrantes de metáforas desaforadas y empedrados de citas de tercera mano, por lo general interpretadas torcidamente" (Cancela, Film porteño 128). Nasute explica que la confusión entre cultura y urbanidad se debe a una concepción de la cultura como formas de cortesía. La carta termina con una exhortación desesperada: “¡Por Dios! que los diputados — sobre todo los de la mayoría - insulten, pero que no hagan metáforas" (129).

En otro momento, un narrador en primera persona, secretario de un conocido abogado y político, cuenta la historia de una visita espectral. Mientras el político - que se parece mucho al Dr. Izquierdo de Historia funambulescapractica su discurso frente a un espejo, llegan tres hombres que aducen haber sido citados. El texto juega con las acepciones del término citar. Los tres hombres son las sombras de Aristóteles, Kant y Spencer, autores a los que acude el político en busca de citas para ornamentar sus discursos. Como el doctor no los reconoce se retiran indignados comentando: "Así son los argentinos: citan a las personas que no conocen y faltan a las citas de las que conocen..." (203).

Film porteño lleva un título que alude al arte cinematográfico en pleno auge, pero además sintetiza una concepción del texto como una serie de fotogramas, una cadena de imágenes que, impresionadas sobre el papel, componen la historia cívico-política del momento. Los fotogramas dan cuenta del estado de degradación de los sujetos y las instituciones. El texto se presenta como fragmentos del diario íntimo de Agamenón Toribio Nasute-Pedernera, curioso nombre cuyo significado explica el autor en "El hijo de Ulises":

El calificativo de que se deriva - "nasutus" - implica un conjunto de cualidades que armonizan prodigiosamente con la figura tradicional del aventurero griego, pues connota en los escritores romanos de la época clásica, los atributos de sagaz, diestro, burlón, mofador y decidor con arte y con gusto; pero de tal coincidencia no debe responsabilizarse al autor de este libro. (7) 
Nasute es una criatura imaginada por el cronista de La Nación ${ }^{4}$. Cuando se presenta en la mesa electoral y le preguntan la edad, contesta dos meses y tres semanas. Ante el asombro del funcionario, aclara: "—Sí, señor; yo nací en un suelto de La Nación el 9 de diciembre de 1929, pero nací ya adulto y con ideas propias. Soy el único constitucionalista ingénito de la República" (89). En gran parte de la novela, el autor-cronista y el personaje dialogan sobre temas políticos, históricos y literarios. Aunque su única obra se inscribe en el género "diario íntimo", Nasute es - de acuerdo con su creador - un "periodista nato", "porque se apasiona por los asuntos públicos mucho más que por los suyos propios, y sin ser político, ni hombre de negocios, ni 'sportsman', ni arquitecto, ni asesino, se interesa por la política, los empréstitos, el resultado de las carreras, la caída de las cornisas y el estado de las investigaciones sobre el último crimen" (26).

Una cantidad de inteligentes estrategias humorísticas produce efectos sorpresivos y disparatados. La prosa literaliza metáforas, pergeña definiciones y contra-definiciones, toma refranes al pie de la letra, juega con acepciones diferentes de una misma palabra o conceptos, materializa consignas políticas y conceptos jurídicos, apuesta de modo permanente al artificio desplegando problemas de autoría, de construcción de los personajes y del universo ficcional, y del papel del lector y del autor, entre otros: "Nasute-Pedernera es una creación de la inteligencia. Ha surgido, ya casi adulto, del cerebro de su padre. Ha surgido como Minerva, pero... sin armas" (172).

El personaje se independiza a tal punto que el mismo autor ignora su paradero. Cuando el cronista, apretado por el público que reclama la presencia de Nasute, va a la buhardilla donde vive, lo encuentra ante un espejo dedicado a la extraña tarea de depilarse la lengua. El personaje representa en su cuerpo y con su cuerpo la expresión popular "no tener pelos en la lengua", que significa decir todo lo que se quiere, sin censuras. La sorpresa del cronista se acentúa cuando observa que "en el lugar de los ojos - aquellos vivaces ojos suyos-aparecían dos cuencas azules cruzadas por una franja blanca en cuyo centro lucían dos soles de oro" (189). Son anteojos nacionalistas, responde Nasute, "para tener, en todo momento una visión patriótica". El capítulo II lleva por título "La voz de la urna",

4 Otros pasajes afirman la realidad del personaje: "Una revista de esta capital consagrada a altas especulaciones estéticas y filosóficas se ha permitido poner en duda la realidad de la existencia de Nasute-Pedernera. Se ha arriesgado a llamarle 'precoz y abstracto personaje' y augurarle que 'acabará volviéndose socialista independiente' con lo cual 'podrá pertenecer eternamente a la minoría"' (101). El cronista le envía la página y el personaje responde en una carta dirigida al "amigo cronista"; el personaje recurre al lema cartesiano - "pienso luego existo"- para despachar un pensamiento político sobre "la montonera electoral". 
referencia obvia a la expresión "las urnas hablaron" para aludir a un determinado resultado electoral mientras se precisa la fecha, 7 de septiembre de 1930, día posterior al golpe militar de Uriburu.

En este contexto, el cronista examina los objetos que componen la Pinacoteca Federal Republicana. Es uno de los momentos de mayor densidad política. Nasute ha armado un museo republicano donde se acumulan objetos diversos que representan una democracia en descomposición. Los objetos que alberga el museo de la novela son restos inservibles que han dejado los distintos gobiernos, las deserciones de sus compromisos e ideales programáticos. Nasute colecciona desechos del sistema democrático:

De la Pinacoteca Federal Republicana de Nasute no quedaban sobre la blanca pared sino los escudos de Entre Ríos y San Luis. En el lugar de los diez escudos ausentes, como enormes insectos, manchaban el panel diez enormes clavos.

- ¿Y esos clavos, Nasute?

Agamenón entró la lengua.

- Son los que han dejado los gobiernos depuestos. Fíjese en los de La Rioja y de Santiago; son enormes... (190)

La expresión "es un clavo" alude a la inutilidad de algo o alguien; "quedarse con un clavo" significa ganar un problema. Ineficientes, los gobiernos provinciales han legado a la nación solo conflictos y deudas. El cronista repara en una espada envainada, cuyo referente es un discurso de Uriburu en el que exhorta: "envainemos la espada y que hablen las urnas" (190). Y finalmente, la prosopopeya de una urna parlante que entona una canción ya conocida subraya la eterna repetición de los errores. En esta historia circular, las revoluciones no originan siquiera modestos cambios.

En otro momento, el cronista encuentra a Nasute que ha vuelto de viaje con algunos objetos para su museo. Invitado por su personaje, el autor describe una especie de gran mercado donde los objetos se amontonan al azar. En el singular cambalache, se hallan los objetos - que materializan propuestas, compromisos y promesas- abandonados por los distintos partidos políticos: los socialistas han olvidado ni más ni menos que su proyecto, "el programa máximo y la representación profesional"; los demócratas, un fusil, "única arma cívica tolerada por los demócratas" y un "bombo personalista". Hay también unas esferas colgadas del techo que resultan ser las garantías constitucionales suspendidas (195).

Quisiera detenerme en los fragmentos titulados "Semana de holgorio"-que se extienden entre el $1^{\circ}$ y el 6 de marzo de 1930. En esa fecha, se realizan las elecciones nacionales donde pierde el oficialismo. La prosa desgrana con acentos 
irónicos ataques al partido radical. Son los meses previos al derrumbe final que llegará con el golpe de septiembre. Los hechos de 1930 se recortan sobre los de 1919. En Tres relatos porteños, su primer libro de cuentos de 1922, Cancela incluye "Una semana de holgorio". El texto se había publicado en un fascículo de La Novela Semanal, del 10 de febrero de 1919, a pocos días de los tremendos sucesos. La trama tiene lugar durante los acontecimientos que la historiografía denomina "Semana Trágica". En enero de 1919, en Buenos Aires, estalla una huelga en los Talleres Metalúrgicos Vasena. Los disturbios culminan con una represión policial que deja varios muertos y heridos. Ante los hechos, las federaciones obreras convocan a una huelga general a partir del 9 de enero. En el entierro de los caídos, mientras hablan los delegados, la policía abre fuego sobre los asistentes. A partir de ese momento, las revueltas se agudizan por semanas, dejando un saldo de centenares de víctimas.

El relato de Cancela comienza el primer día de huelga. Uno de sus hallazgos reside en que los hechos están narrados en primera persona, desde el punto de vista distanciado y la voz de un miembro de la oligarquía, Julio Narciso Dilon - que aparecerá en textos posteriores - al que la huelga lo obliga a cambiar sus trayectos por la ciudad; las circunstancias lo arrastran del habitual recorrido al hipódromo hacia barrios convulsionados y lejanos.

El significante holgorio articula, entonces, dos acontecimientos centrales en los procesos políticos nacionales y en la vida del partido radical. Huelga y holgorio provienen de la misma palabra, holgar, que significa estar ocioso y también divertirse, haciendo converger la banalidad — de las clases oligárquicas, los estamentos políticos y también de las prácticas cívicas-, las luchas fútiles y las vidas sacrificadas en un sinsentido absoluto. Las aventuras terminan en farsa gigantesca protagonizada por personajes tan adelgazados que replican al mismo Nasute-Pedernera.

En el cuento "El mitin del 6 de septiembre de 1930" - que también recoge Tres relatos porteños - describe las aventuras urbanas del diputado oficialista Remo A. Digiorno que resume el tipo del político arribista, falto de escrúpulos y de escasa inteligencia; un representante del pueblo tan desvinculado de la realidad que cree que la multitud que encuentra en las calles el 6 de septiembre, fecha del golpe de Uriburu, va a un mitin partidario. En el colmo de la ceguera, comenta: "—¡Qué suerte tiene el viejo! ¡Cuantas más macanas hace, más le responde la gente!"' (163).

Para terminar, tomo una escena de Film porteño que sintetiza el estado de la política nacional. El cronista y don Eremita, tío de Nasute, alarmados por las conductas del joven resuelven ir a su casa. Cuando penetran en la habitación, lo 
encuentran sentado en el suelo deshaciendo el colchón de laureles para evitar la tentación de volver a dormirse en ellos. A la pregunta formulada por el cronista sobre el curioso hecho de que Nasute porta en una mano una ramita de olivo y en la otra una rama mucho mayor de acebuche, contesta:

- Ya lo ve: proclamo la concordia nacional - dijo Nasute-Pedernera, agitando como un cascabel la ramita de olivo que llevaba en la diestra.

${ }_{-} \dot{\mathrm{Y}}$ ese garrote?

- Es para garantizar la concordia. (217)

El mismo instrumento sirve para la paz y para la guerra. Además de ser una virtud y una aspiración cívica, La Concordia era el nombre del partido político que gobernó entre 1932 y 1943, fruto de una alianza conservadora formada por el Partido Demócrata Nacional, la Unión Cívica Antipersonalista y el Partido Socialista Independiente.

Los fotogramas de este film porteño ponen en jaque el sistema republicano entero, apostando a la implosión de sus instituciones presentes, pasadas y futuras. Quizás por esa insistencia en una literatura que potencia el gesto nihilista, Arturo Cancela haya sido olvidado en la historia literaria argentina.

\section{Obras citadas}

Antelo, Raúl. "Cancela: humor, nacionalismo e historia". Yrigoyen entre Borges y Arlt (1916-1930). Comp. Graciela Montaldo. Buenos Aires: Contrapunto, 1989. 247-266. Impreso.

Bernini, Emilio. "Arturo Cancela: una minoridad de diletante". Historia crítica de la literatura argentina. Volumen VI. Dir. María Teresa Gramuglio. Buenos Aires: Emecé Editores, 2002. 245-257. Impreso.

Cancela, Arturo. Film porteño. Buenos Aires: Librerías Anaconda, 1933. Impreso. "Helenismo en la pampa". La vida literaria III.23 (agosto de 1930):12. Impreso. Historia funambulesca del profesor Landormy. Buenos Aires: Centro Editor de América Latina, 1982. 2 volúmenes. Impreso. Tres relatos porteños y tres cuentos de la ciudad. Buenos Aires: Espasa-Calpe Argentina, 1946. Impreso.

Homenaje a Buenos Aires en el cuarto centenario de su fundación. Buenos Aires:

Municipalidad de la ciudad de Buenos Aires, 1936. Impreso. 